\title{
ACHIEVEMENT GOALS AND SELF-DETERMINATION IN ADULT FOOTBALL PLAYERS - A CLUSTER ANALYSIS
}

\author{
Hugo Sarmento ${ }^{1}$, Miguel Peralta ${ }^{2}$, Liam Harper ${ }^{3}$, Vasco Vaz ${ }^{1}$, and Adilson Marques ${ }^{4}$ \\ ${ }^{1}$ Research Unit for Sport and Physical Activity (CIDAF), Faculty of Sport \\ Sciences and Physical Education, University of Coimbra, Portugal \\ ${ }^{2}$ Faculdade de Motricidade Humana, Universidade de Lisboa, Lisbon, Portugal \\ ${ }^{3}$ Division of Sport and Exercise Sciences, University of Huddersfield, Huddersfield, UK \\ ${ }^{4}$ Centro Interdisciplinar de Estudo da Performance Humana, \\ Faculdade de Motricidade Humana, Universidade de Lisboa, Lisbon, Portugal
}

Original scientific paper

https://doi.org/10.26582/k.50.1.1

UDC: 159.9: 796.332- 053.81

\begin{abstract}
:
To better understand the relationship between aspects of motivation and performance level in adult football players, this study aimed to identify differences in motivation among different motivational profiles created by means of hierarchical cluster analysis. The participants were 304 adult football players ( 90 professionals, 144 semi-professionals, 70 amateurs, age: $25.4 \pm 4.6$ years). Participants completed the Task and Ego Orientation in Sports Questionnaire and the Self-Regulation Questionnaire. Based on the constructs of the questionnaires, cluster analyses were performed. Chi-square was used to determine any relationships between the players and clusters. Four different clusters were identified. There was no typical motivational profile for football players of different competition levels. However, the differences in all four clusters represented specific characteristics of football players of different competition levels most represented in each respective cluster. Cluster 1, which was the most adaptive, was not related to any competition level. On the other hand, professional athletes were significantly less represented in the least adaptive motivational profile (Cluster 4). The results highlight the complex relationship between competition and sporting motivation. Identifying the motivational profile characteristics of football players who can reach higher competition levels presents itself as a future research opportunity.
\end{abstract}

Key words: motivation, soccer, adults, sport

\section{Introduction}

Motivation plays a fundamental role in sports as it influences why and how athletes engage in the activities they have chosen, affecting the quality of their engagement and ultimately their performance (Chin, Khoo, \& Low, 2012; Olmedilla, Ortega, Andreu, \& Ortín, 2010; Shah \& Gardner, 2008). Self-determination theory (Deci \& Ryan, 1985) and the achievement goal theory (Nicholls, 1989) are two of the most common theoretical approaches to studying achievement motivation in sport and physical activity (Fenton, Duda, \& Barrett, 2016; Zuber, Zibung, \& Conzelmann, 2015).

According to the achievement goal theory, there are two different goal orientations: (1) Ego Orientation - focusing on displaying one's superiority to other people with the aim of demonstrating competence in relation to his/her peers, and (2) Task Orientation - the person is more likely to define success or competence in terms of mastery or task improvement (Nicholls, 1989). Since these are orthogonal concepts, it is possible for individuals to be oriented to both of them (Cumming, Hall, Harwood, \& Gammage, 2002; Lochbaum, Çetinkalp, Graham, Wright, \& Zazo, 2016; Wang, Liu, Sun, Lim, \& Chatzisarantis, 2010). An extensive quantitative review in competitive sport (including football) of the Task and Ego Orientations in Sport Questionnaire (TEOSQ) and Perceptions of Success Questionnaire (POSQ) has been published by Lochbaum et al. (2016). Analyses using different moderator variables (e.g., sex, sport level, sport type and collective/individualistic countries) provided important results and different research/practical directions that allow researchers to advance the study of this specific area. However, the synthesis of the 260 studies that met the inclusion criteria highlighted that the two questionnaires did not agree across a number of tested hypotheses. Thus, 
the second quantitative review (Lochbaum, Zazo, Çetinkalp, Wright, Graham, \& Konttinen, 2016) has been published in order to examine whether correlates of the two achievement goal orientations were moderated by the two measures.

In self-determination theory (Deci \& Ryan, 1985), the reasons for motivated actions are distinguished according to the location of a person's perceived locus of causality, or to what extent he/she is self-determined. Deci and Ryan (1985) proposed a multidimensional concept of a motivational continuum with three main dimensions: (1) intrinsic motivation; (2) extrinsic motivation, and; (3) amotivation. Additionally, extrinsic motivation has been split into four different levels: external regulation, introjected regulation, identified regulation and integrated regulation. Conceptual links between the self-determination theory and the achievement goal theory have been observed in several studies (Chin, et al., 2012; Ntoumanis, 2001; Zuber et al., 2015) demonstrating that task oriented individuals are more self-determined and more intrinsically motivated, whereas ego oriented individuals are less self-determined and more extrinsically motivated (Ntoumanis, 2001). Through an extensive quantitative review, Lochbaum, Zazo et al. (2016) found a significant and small to moderate relationship in meaningfulness between the task goal orientation and amotivation $\left(\mathrm{r}_{\mathrm{w}}=-.13\right)$, extrinsic motivation $\left(\mathrm{r}_{\mathrm{w}}=.20\right)$, external regulations $\left(\mathrm{r}_{\mathrm{w}}=.12\right)$, internal regulations $\left(\mathrm{r}_{\mathrm{w}}=.34\right)$ and intrinsic motivation $\left(\mathrm{r}_{\mathrm{w}}=.47\right)$. On the other hand, the ego goal orientation was significantly loosely related in meaningfulness to amotivation $\left(\mathrm{r}_{\mathrm{w}}=16\right)$, extrinsic motivation $\left(\mathrm{r}_{\mathrm{w}}=.28\right)$, external regulation $\left(\mathrm{r}_{\mathrm{w}}=.21\right)$, and intrinsic motivation $\left(\mathrm{r}_{\mathrm{w}}=.14\right)$.

Nevertheless, based in the orthogonality of the two achievement goals, examining task and ego goals separately may not yield a true picture, therefore it is important to analyze goal profiles where possible (Fox, Goudas, Biddle, Duda, \& Armstrong, 1994). In order to approach motivation from a multidimensional perspective, investigations have used profile analysis to examine dynamics of the motivational constructs, such as goal orientation and self-determination (Chian \& Wang, 2008; Etnier, Sidman, \& Hancock, 2004; Gillet, Vallerand, \& Paty, 2013; Hodge \& Petlichkoff, 2000; Wang, et al., 2010). Results may differ when analysing goals separately compared to profiles of goals combinations. Previous studies in this area (i.e., Fox, et al., 1994; Hodge \& Petlichkoff, 2000) have used mean or median split to create four groups: hightask/high-ego (hi/hi), high-task/low-ego (hi-T/ lo-E), high-ego/low-task (hi-E/lo-T), and low-task/ low-ego (lo/lo). Although these two procedures are efficient, they enforce a structure on the data that might not reflect reality. One problem related with this technique is that scores close to the median or mean are classified arbitrarily as either high or low when they might actually represent average scores on the task and/or ego orientations. In recent years cluster analysis has increased in popularity as an analytical procedure to examine varying goal profiles in sport psychology as it goes beyond the crude procedures of median and mean split through the generation of subgroups that fit the data satisfactorily by maximizing between-cluster differences and minimizing within-cluster differences (Hodge \& Petlichkoff, 2000)

Using cluster analysis, several authors have analysed constructs from different theories (e.g., self-determination theory and achievement goal theory) in order to identify subgroups with different motivational profiles in physical activities and sports (Almagro, Sáenz-López, \& Moreno-Murcia, 2012; Etnier, et al., 2004; Hodge \& Petlichkoff, 2000; Wang, et al., 2010). These studies have shown that cluster analysis is a valid method that can identify homogeneous motivational profiles.

Although little is known about which types of motivation positively contribute to performance, it is generally considered that motivation is conducive to performance. In this sense, it is important to adopt a person-oriented approach (e.g., using cluster analysis) rather than a variable-oriented approach (e.g., using self-determination index) to examine how different forms of motivation combine to generate different motivational profiles (Gillet, et al., 2013).

Despite several studies using this type of analysis, most of them have focused on school-aged children (Castillo, Balaguer, \& Duda, 2000; Chian \& Wang, 2008; Wang, et al., 2010). Studies focusing on adult athletes (Balaguer, Castillo, \& Duda, 2008; Etnier, et al., 2004; Fonseca \& Paula-Brito, 2000) and particularly elite adult athletes are scarce (Gillet, et al., 2013; Mallet \& Hanrahan, 2004), as stated in two recently published extensive reviews (Lochbaum, Çetinkalp, et al., 2016; Lochbaum, Zazo, et al. 2016).

Different authors have identified a diverse number of profiles in their samples due to the different purposes of their investigations and techniques used for establishing the profiles. In a sporting context, Hodge and Petlichkoff (2000) were not able to locate any extreme goal profiles (using a mean-split procedure) in adolescent and adult rugby players. However, the authors identified four profiles through cluster analysis. Perceived rugby ability/competence discriminated the high-ego/ moderate-task and low-ego/moderate-task groups, with the former reporting a greater perceived ability/competence. In a sample of youth football players, Smith, Balaguer and Duda (2006) observed four profiles that closely matched those observed by Hodge and Petlichkoff (2000). The achievement goal profile differences were found for almost all 
variables (task and ego involvement climate, peer acceptance, friendship ability and satisfaction), with a general trend for those reporting a relatively lower task goal orientation to exhibit less adaptive responses. Almagro et al. (2012) found two profiles in Spanish adolescent athletes: i) highly motivated profile, with high scores in both forms of motivation, self-determined (intrinsic motivation and identified regulation) and non-self-determined motivation (introjected and external regulation), and; ii) a moderately motivated profile, with moderate scores (around three and four) in forms of self-determined and non-determined motivation. Although the authors highlighted the importance of clusteranalysis to determine whether similar goal-orientation profiles can be identified in specific groups (e.g., elite versus recreational; elite versus novice) of athletes in different sports (e.g., football), there exist very few studies that have investigated top level athletes, namely, top level football players.

In a study of adult tennis athletes, Gillet et al. (2013) investigated the situational motivational profiles corresponding to high and low levels of performance in a real-life setting and found the presence of three clusters (moderate-autonomous/ high-controlled; high-autonomous/high-controlled; high-autonomous/low-controlled). The authors concluded that the least self-determined profile predicted the lowest levels of performance.

Despite football being the most popular sport worldwide (Sarmento, et al., 2014), it is surprising that motivational aspects commonly related to sports performance have not been studied in-depth; particularly in elite players (for a review, see Lochbaum, Çetinkalp, et al., 2016; Lochbaum, Zazo, et al. 2016). Modern football provides an environment where athletes may be more extrinsically motivated (due to finances) than intrinsically motivated, for enjoyment or personal achievement (Horn, 2001). Naturally, all athletes have high intrinsic motivation (enjoyment; passion for the game). However, the professional football environment may decrease this type of motivation.

Cognitive evaluation theory suggests that the elite sports environment predominantly focuses on winning and with large financial considerations, leading to lower levels of self-determination and, consequently, lower levels of intrinsic motivation (Mallet \& Hanrahan, 2004). Laboratory and field research has demonstrated that elite competitions have a negative influence on intrinsic motivation. Furthermore, perceived performance climate attenuates a positive relationship between the mastery climate and increased intrinsic motivation (Buch, Nerstad, \& Safvenbom, 2017). Nevertheless, in an investigation by Mallet and Hanrahan (2004), the authors identified that elite athletes view financial compensation as more related to their self-competence than as behaviour modifiers.
Elite sports, which are largely focused on winning and financial rewards associated with victories, may potentially decrease self-determined types of motivation and may move the causality locus from internal to external. Nevertheless, there are some aspects of elite sports that promote selfdetermination, and perception of competence and bonding, which, in return, may promote an internal causality locus and self-determined types of motivation (Deci \& Ryan, 1985). Mallet and Hanrahan (2004) suggest that the causality locus may move from external to internal as athletes mature; and, as a result, financial compensation and rewards lose motivational strength. The perception of competence and being accepted by others represent a more powerful motivational strength. Additionally, Gillet et al. (2013) suggested that cluster analysis with different samples of top performers (tennis players) reveals somewhat different profiles because the nature of the social context could have an impact on the development of motivational profiles characterized by high levels of controlled motivation.

To better understand the relationship between aspects of motivation and the performance level of adult footballers, the aim of this study was to identify differences in motivation using different motivational profiles established by hierarchical cluster analysis. Additionally, the relationship between achievement goals and different types of motivation proposed by the self-determination theory were analysed.

\section{Methods}

\section{Participants and procedures}

Data were collected from a total of 21 football teams competing in the first and second division of the Portuguese professional football league $(n=6)$, second division $\mathrm{B}$ and third division of the national championships $(\mathrm{n}=9)$, and regional championships $(\mathrm{n}=6)$. The sample consisted of 304 football players ranging in age from 17 to 39 years $\left(\mathrm{M}_{\text {age }}=25.4 \pm 4.6\right.$ years). Consent from the coaches and players were obtained before data collection. The protocol and procedures for this study were approved by the Research Ethics Committee of the authors affiliated universities.

\section{Measures}

\section{Achievement goal orientations}

The Portuguese version (Fonseca \& Biddle, 1995; Fonseca \& Paula-Brito, 2000) of TEOSQ (Duda \& Nicholls, 1992) was used to assess athletes' dispositional goal orientations. The stem for the 13 items was "I feel most successful in the sport when..." and assessed ego (e.g., "... I am the only one capable of doing this", $\mathrm{N}_{\text {items }}=6$ ), and task orientation (e.g., “... I do my best", $\mathrm{N}_{\text {items }}=7$ ). The 
replies were rated on a Likert scale, in which each item had a response range from one (completely disagree) to five (completely agree). An adequate internal consistency was obtained for each subscale, with the Cronbach's alpha coefficients of .80 identified for both the task and ego orientation subscales.

\section{Perceived autonomy - Self-Regulation Questionnaire}

To measure players perceived autonomy, the Portuguese version (Fonseca \& Biddle, 1997) of the Self-regulation Questionnaire (SRQ) (Ryan \& Connell, 1989) was used. The SRQ is composed of 17 items, grouped into five dimensions: (1) amotivation (e.g., "I do not have any reason to do sports", $\mathrm{N}_{\text {items }}=3$ ); (2) external regulation (e.g., "I do sports because other people tell me I should do it", $\mathrm{N}_{\text {items }}=4$ ); (3) introjected regulation (e.g., "I feel guilty when I do not practice sports", $N_{\text {items }}=4$ ); (4) identified regulation (e.g., "I valorise the benefits of practicing sports", $\mathrm{N}_{\text {items }}=3$ ); and (5) intrinsic regulation (e.g., "I practice sports because it is fun", $\mathrm{N}_{\text {items }}=3$ ). Answers were given on a five-point Likert scale, and adequate internal consistency was obtained for each subscale, with the Cronbach's alpha coefficients for the different dimensions ranging between .70 and .80 .

The questionnaires were given to each athlete in a quiet place, without distractions. Each participant took 15-20 minutes to complete the questionnaires and responses were kept anonymous. Participants were informed about the general purpose of the study and told that their identities would be kept strictly confidential and that all the items in the questionnaires should be answered as honestly as possible. The participants encountered no problems when completing either of the questionnaires.

\section{Data analysis}

Frequencies, means, and standard deviations were calculated to characterize the participants. Normality for the dimensions of the Portuguese versions of the TEOSQ and SRQ was tested by the Kolmogorov-Smirnov test of normality. All missing data and outliers were eliminated. Pearson's $r$ coefficient was used to calculate the correlations between the mean values of the variables.

Variables were standardized using z-score $(\mathrm{M}=0, \mathrm{SD}=1)$. Athletes were grouped/classified using hierarchical and non-hierarchical cluster analysis. Firstly, the nearest neighbour hierarchical cluster analysis was conducted, using the squared Euclidian distance as a measure of dissimilarity. The R-square was used as criteria for the retention of the number of clusters. From this analysis, four clusters were retained. For the validation and classification of the athletes in the four clusters retained, a k-Means non-hierarchical cluster analysis was conducted. Differences between clusters, for the dimensions of the Portuguese versions of the TEOSQ and SRQ, were tested by the one-way ANOVA test, followed by the Tukey's HSD posthoc test. Chi-square test was used to determine if the competitive level of the athletes was independent of the clusters. All analyses were performed using IBM SPSS v.23.

\section{Results}

\section{Descriptive statistics and inter correlations}

Table 1 presents the participant's characteristics as mean age (25.5 \pm 4.5 years), mean years of experience as a footballer ( $7.7 \pm 4.8$ years), competitive level, playing position, and nationality.

Table 1. Participant characteristics $(N=315)$

\begin{tabular}{lcc}
\hline & No./M \pm SD & $\%$ \\
\hline Age & $25.4 \pm 4.5$ & \\
Football experience (years) & $7.8 \pm 4.8$ & \\
Competitive level & & \\
$\quad$ Amateur & 70 & 23.0 \\
$\quad$ Semi-professional & 144 & 47.4 \\
$\quad$ Professional & 90 & 29.6 \\
Position & & \\
$\quad$ Goalkeeper & 31 & 10.2 \\
$\quad$ Defender & 113 & 37.2 \\
$\quad$ Midfielder & 104 & 34.2 \\
$\quad$ Forward & 56 & 18.4 \\
Nationality & & \\
$\quad$ Portuguese & & \\
Other from Europe & 267 & 87.8 \\
Brazilian & 3 & 1.0 \\
$\quad$ African & 25 & 8.2 \\
& 9 & 3.0 \\
\hline
\end{tabular}

Internal consistency and mean values for all the dimensions of goal orientation and perceived autonomy are presented in Table 2. In general, the athletes reported high scores in task orientation, and in the self-determined components of motivation (intrinsic motivation and identified regulation). Task and ego orientations were weakly related, supporting the orthogonal nature of the two goals. Task orientation was significantly correlated with intrinsic motivation $(\mathrm{r}=.4, \mathrm{p}<.001)$ and identified regulation $(\mathrm{r}=.5, \mathrm{p}<.001)$, while ego orientation was significantly correlated (although weakly) with introjected regulation $(\mathrm{r}=.15, \mathrm{p}<.01)$.

\section{Cluster analysis}

Table 3 shows the mean values, standard deviations and z-score used to create the clusters. Cluster profiles are presented in Figure 1. To determine if the profiles were classified as high or low when comparing clusters, z-score values near \pm 0.5 were 
Table 2. Internal consistency and mean values for all dimensions of goal orientation and perceived autonomy

\begin{tabular}{|c|c|c|c|c|c|c|c|c|c|}
\hline & $\alpha$ & $\mathrm{M} \pm \mathrm{SD}$ & 1 & 2 & 3 & 4 & 5 & 6 & 7 \\
\hline 1. Task & 0.87 & $4.16 \pm 0.53$ & 1.00 & -.03 & $.42^{* * *}$ & $.51^{* * *}$ & $.26^{* * *}$ & -.07 & $-.26^{\star * *}$ \\
\hline 2. Ego & 0.89 & $2.60 \pm 0.86$ & & 1.00 & .04 & .04 & $.15^{* *}$ & .08 & -.03 \\
\hline 3. Intrinsic & 0.73 & $4.19 \pm 0.63$ & & & 1.00 & $.57^{* * *}$ & $.25^{\star * *}$ & -.07 & $-.29^{\star \star \star}$ \\
\hline 4. Identified & 0.75 & $4.33 \pm 0.60$ & & & & 1.00 & $.52^{* * *}$ & .06 & $-.27^{* * *}$ \\
\hline 5. Introjected & 0.70 & $3.42 \pm 0.97$ & & & & & 1.00 & $.37^{* * *}$ & .02 \\
\hline 6. External & 0.75 & $1.81 \pm 0.66$ & & & & & & 1.00 & $.45^{\star \star *}$ \\
\hline 7. Amotivation & 0.78 & $1.41 \pm 0.62$ & & & & & & & 1.00 \\
\hline
\end{tabular}

${ }^{*} p<.05,{ }^{* *} p<.01,{ }^{* * *} p<.001$

Table 3. Mean values, standard deviation and z-scores of the four clusters

\begin{tabular}{|c|c|c|c|c|c|c|c|c|c|}
\hline & \multicolumn{2}{|c|}{ Cluster 1} & \multicolumn{2}{|c|}{ Cluster 2} & \multicolumn{2}{|c|}{ Cluster 3} & \multicolumn{2}{|c|}{ Cluster 4} & \multirow{2}{*}{$\mathrm{p}$} \\
\hline & $\mathrm{M} \pm \mathrm{SD}$ & $z$ & $\mathrm{M} \pm \mathrm{SD}$ & $z$ & $\mathrm{M} \pm \mathrm{SD}$ & $z$ & $\mathrm{M} \pm \mathrm{SD}$ & $z$ & \\
\hline Task & $4.56 \pm 0.40$ & 0.76 & $4.07 \pm 0.41$ & -0.17 & $3.90 \pm 0.44$ & -0.49 & $3.53 \pm 0.44$ & -1.18 & $<.001^{\mathrm{b}}$ \\
\hline Ego & $2.57 \pm 0.96$ & -0.04 & $2.82 \pm 0.82$ & 0.26 & $2.46 \pm 0.75$ & -0.16 & $2.49 \pm 0.67$ & -0.12 & $.045^{c}$ \\
\hline Intrinsic & $4.65 \pm 0.46$ & 0.74 & $4.00 \pm 0.45$ & -0.30 & $3.96 \pm 0.56$ & -0.36 & $3.40 \pm 0.50$ & -1.26 & $<.001^{d}$ \\
\hline Identified & $4.84 \pm 0.26$ & 0.86 & $4.28 \pm 0.37$ & -0.08 & $3.90 \pm 0.55$ & -0.72 & $3.57 \pm 0.45$ & -1.28 & $<.001^{b}$ \\
\hline Introjected & $3.99 \pm 0.84$ & 0.58 & $3.75 \pm 0.53$ & 0.33 & $2.50 \pm 0.79$ & -0.94 & $3.03 \pm 0.57$ & -0.40 & $<.001^{\mathrm{e}}$ \\
\hline External & $1.71 \pm 0.64$ & -0.14 & $2.30 \pm 0.48$ & 0.74 & $1.29 \pm 0.38$ & -0.77 & $2.43 \pm 0.50$ & 0.94 & $<.001^{\mathrm{f}}$ \\
\hline Amotivation & $1.09 \pm 0.24$ & -0.53 & $1.81 \pm 0.62$ & 0.64 & $1.14 \pm 0.28$ & -0.44 & $2.55 \pm 0.58$ & 1.84 & $<.001^{\mathrm{g}}$ \\
\hline
\end{tabular}

a Tested by ANOVA, followed by post-hoc Tukey's HSD.

${ }^{b}$ All clusters are statistically different.

c Clusters 2 and 3 are statistically different from each other.

${ }^{d}$ Clusters 1 and 4 are statistically different from each other and statistically different from all the other clusters.

e Clusters 3 and 4 are statistically different from each other and statistically different from all the other clusters.

${ }^{f}$ Clusters 1 and 3 are statistically different from each other and statistically different from all the other clusters.

${ }^{9}$ Clusters 2 and 4 are statistically different from each other and statistically different from all the other clusters.

used. Z-scores near \pm 0.3 were considered moderate. Athletes from Cluster $1(\mathrm{n}=113)$ had high scores for task orientation, intrinsic motivation, identified regulation and introjected regulation, and high negative scores for amotivation. Cluster $2(n=80)$ was characterized by presenting moderate scores in most of the analysed variables, shifting between positive scores (ego orientation, introjected regulation) and negative scores (task orientation, intrinsic motivation, identified regulation). External regulation and amotivation were the only high scores in this cluster. Cluster $3(\mathrm{n}=96)$ presented negative scores in all variables. This group of athletes had moderate negative scores for task orientation, intrinsic motivation, and amotivation, and high negative scores for ego orientation, identified regulation, introjected regulation, and external regulation. Athletes from Cluster $4(n=25)$ obtained high scores for external regulation and amotivation while having high negative scores for task orientation, intrinsic motivation, and identified regulation, suggesting this group was the most amotivated.
To examine the characteristics of each profile an ANOVA analysis was performed (Table 3). The significant differences were found between the clusters for all the analysed variables.

The significant differences between the clusters regarding competitive level were verified $(\chi 2(6)=19.130, p=.004)$ (Table 4). Amateurs were less represented in Cluster 2 and more represented in Cluster 3 than professionals and semi-professionals. Professional athletes were more represented in Cluster 4 than amateur and semi-professional athletes.

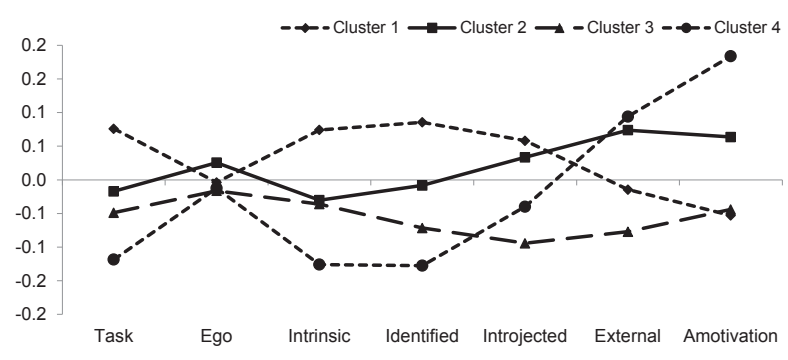

Figure 1. Cluster profiles for the four clusters solution. 
Table 4. Athletes cluster distribution according to competitive levels

\begin{tabular}{|c|c|c|c|c|c|c|c|c|c|}
\hline & \multicolumn{2}{|c|}{ Cluster 1} & \multicolumn{2}{|c|}{ Cluster 2} & \multicolumn{2}{|c|}{ Cluster 3} & \multicolumn{2}{|c|}{ Cluster 4} & \multirow{2}{*}{$\mathrm{p}^{\mathrm{a}}$} \\
\hline & $\mathrm{n}$ & $\%$ & $\mathrm{n}$ & $\%$ & $\mathrm{n}$ & $\%$ & $\mathrm{n}$ & $\%$ & \\
\hline Competitive level & & & & & & & & & .004 \\
\hline Amateur & 22 & 31.4 & 10 & $14.3^{\mathrm{b}}$ & 29 & $41.4^{c}$ & 9 & 12.9 & \\
\hline Semi-professional & 58 & 40.3 & 39 & 27.1 & 33 & 22.9 & 14 & 9.7 & \\
\hline Professional & 33 & 36.7 & 31 & 34.4 & 24 & 26.7 & 2 & $2.2^{\mathrm{d}}$ & \\
\hline Total & 113 & 37.2 & 80 & 26.3 & 86 & 28.3 & 25 & 8.2 & \\
\hline
\end{tabular}

a Tested by chi-square.

b Standardized residuals $=-2.0$

c Standardized residuals $=2.1$

d Standardized residuals $=-2.0$

\section{Discussion and conclusions}

The aim of this study was to identify motivational profiles of Portuguese football players from different competitive levels, based on self-determination theory (Deci \& Ryan, 1985) and achievement goal theory (Nicholls, 1989). To the best of our knowledge, this is the first study to analyze these variables in professional football players.

Similar to other studies (Chian \& Wang, 2008; Etnier, et al., 2004; Hodge \& Petlichkoff, 2000; Wang, et al., 2010), our results showed that athletes seemed to be more oriented to demonstrating competence about themselves rather than demonstrating competence about their peers. This can be construed as a positive result, as higher task orientation levels are associated with persistence and commitment in sports (Roberts, 2001). Lochbaum, Çetinkalp et al. (2016) found estimated mean values of $4.15 \pm 0.30$ and $3.04 \pm 0.51$ for task and ego orientations, respectively. The results from this group of Portuguese footballers are very similar for task orientation, but they displayed lower mean levels for ego orientation, when looking at the overall results of the reviewed studies, including POSQ and TEOSQ. Nevertheless, the analyses of Lochbaum, Çetinkalp, et al. (2016), using the TEOSQ, reveal very similar results with those found in our study ( $4.09 \pm 0.28$ and $2.92 \pm 0.48$ for task and ego orientations, respectively). Additionally, other similar scores can be found in this review of literature, when assessing the specific analysis performed according the sex, sport level, sport type and collective/individualistic countries (West Europe Countries in our specific case).

Task goal was significantly related to intrinsic motivation, identified regulation and amotivation. The ego goal orientation was significantly related to introjected regulation. The relationships between both the task and ego goal orientations with the different components of motivation are consistent with previous results (e.g., Biddle, Wang, Kavussanu, \& Spray, 2003; Lochbaum, Zazo, et al., 2016, Wang \& Biddle, 2001) and suggest that task orien- tation is more motivationally adaptive, regardless of the level of ego orientation.

Athletes attributed higher scores to higher levels of perceived autonomy. In fact, our results demonstrated a gradual increase of the scores from the most extrinsic to the most intrinsic components of motivation (external regulation, introjected regulation, identified regulation, intrinsic motivation), except for identified regulation, which had higher scores than the intrinsic motivation. The higher levels of identified regulation observed may be related to the fact that most of the participants were professional or semi-professional athletes and were exposed to an elite sports environment. Therefore, more than being involved in football for intrinsic nature reasons (e.g., enjoyment), it is possible that these athletes were involved mostly for the importance, prestige, and value attributed to football. Similar findings were obtained in a study investigating regular sports participation among university students (Wilson, Rodgers, Fraser, \& Murray, 2004). The authors suggested that, in the context of sport, intrinsic motives and participating in the activities by itself were not sufficiently interesting or gratifying to regulate peoples' participation. The authors concluded that identified regulation, intrinsic motivation, and persistence were key predictors of motivational adaptive consequences for practicing sports.

Congruent with previous studies (Gillet, et al., 2013; Hodge \& Petlichkoff, 2000; Smith, Balaguer, \& Duda, 2006), the present study demonstrates that cluster analysis is able to identify subgroups of athletes with differentiated motivational patterns. As stated by Chian and Wang (2008), the present findings and previous research provide ample evidence that motivation is multi-dimensional and cannot be simply classified as "high" versus "low" based on a single variable (e.g., Hodge \& Petlichkoff, 2000). In line with previous research (e.g., Chian \& Wang, 2008; Hodge \& Petlichkoff, 2000), we found no extreme group profiles (hig-ego/hightask or low-ego/low-task) when cluster analysis was used. 
Nevertheless, the analysis of the different motivational profiles presented some interesting results. There was no difference in the competitive level of the athletes in Cluster 1, which was characterized as containing higher task orientation levels. Considering that Cluster 1 is composed of predominately professional and semi-professional athletes, this result was expected. Indeed, according to previous findings, professional and semi-professional athletes are significantly more represented in this type of cluster and also have higher ego orientation levels. Furthermore, higher task orientation levels associated with higher levels of ego orientation are the most adaptive motivational pattern for these athletes (Biddle, 1999; Cumming, et al., 2002; Georgiadis, Biddle, \& Auweele, 2000; Mallet \& Hanrahan, 2004; Roberts, 2001). However, the previous studies by Etnier et al. (2004) have not observed this profile. The profile from Cluster 1 can be considered as the most "motivationally adaptive profile" as it presents high scores for task orientation, is associated with moderate ego orientation scores, and demonstrates higher scores in the most self-determined types of motivation (intrinsic, identified, and introjected), as well as low scores in external motivation and amotivation, when compared to the other clusters' profiles. This suggestion is supported, amongst others, by the results of Gillet et al. (2013), who found that tennis players who had profiles with higher levels of self-determination were more likely to have higher levels of performance.

The profile of Cluster 2 is the most common among high competitive level athletes, presenting higher scores for ego orientation, and combining high scores in the more self-determined components of motivation with relatively high scores in the less self-determined components. Furthermore, amotivation scores were slightly higher in this cluster.

Cluster 1 and Cluster 2 presented the highest scores in introjected regulation. In a study using female athletes, Wilson et al. (2004) concluded that introjected regulation was an important motivational strength, as it seemed to be a strong predictor of behaviours like persistence and effort in physical activity. However, although we suggested that introjected regulation or even external regulation could be related to higher levels of performance in football players, we should take into consideration that less self-determined levels of motivation potentially affected athletes' emotional component related to performance. Athletes with lower self-determined levels of motivation are less likely to have positive feelings towards competition and will generally be more anxious before and after the competition (Perreault \& Vallerand, 1998). Therefore, less self-determined levels of motivation are a "doubleedged sword", as it relates to better performance but has high emotional setbacks. Furthermore, emotional self-regulation resource impairment influences sport performance (Wagstaff, 2014).

Cluster 4 presents less adaptive characteristics for motivation in physical activity and sports. Professional athletes were less represented in this cluster than semi-professional and amateur athletes. This suggests that athletes from lower competitive levels have lower levels of intrinsic motivation and identified regulation, and are more amotivated and susceptible to external types of motivation. However, when interpreting this finding, it must be taken into consideration that only 25 athletes were classified in this cluster and thus characterized by this profile. Nevertheless, it is important to highlight that this group of athletes is one that is at higher risk of dropout from sporting activities (Etnier, et al., 2004). Most of the athletes in Cluster 4 were semi-professional, and it is possible that the high amotivation scores were related to this. Being at a middle stage between professional and amateur sports on the one hand can give access to professionalization, but on the other hand, it is where many athletes finish their careers. Thus, athletes who expect to reach professionalization and fail, and athletes who once were professional athletes and now are at the end of their careers are possibly more externally motivated and amotivated.

The analyses of Cluster 4 cannot be dissociated from the analyses of Cluster 3, where amateurs were the most represented group and the profile was characterized by low levels of amotivation and external motivation. It is plausible that amateur athletes, who practice in harsh conditions after working hours and without financial compensations, are involved in football mostly because of intrinsic motives, such as enjoyment or pleasure for the game.

A few limitations should be noted in the current study. The variables measured were self-reported, which may lead to a common method variance bias. However, as stated by Li, Wang, Pyun, and Kee (2013), self-reported data may be the most valid measurement method in this type of study. Participants were deemed to be in the best position to report on their levels of motivation. Additionally, the data were collected in different phases of the sporting season, before or after the training sessions, and different situational variables might have influenced the findings. Future research should also analyse relationships between achievement goals theory and self-determination theory and other variables, such as emotions, behaviours, achievements strategies, personality traits, etc., in order to more objectively identify which clusters lead to more adaptive/maladaptive outcomes.

The findings from this study suggest that there is no typical motivational profile for football players from different competitive levels. However, athletes 
from higher competitive levels were more represented in clusters characterized by the high task orientation scores associated with moderate ego orientation scores and relatively high scores in the most self-determined types of motivation. Athletes from Cluster 4 were the least motivationally adaptive and presented the greatest risk of dropout from football. Therefore, this group of athletes should be the target of specific interventions that aim to prevent dropouts.

\section{References}

Almagro, B., Sáenz-López, P., \& Moreno-Murcia, J. (2012). Perfiles motivacionales de deportistas adolescentes Españoles. [Motivational profiles of Spanish adolescent athletes. In Spanish.] Revista de Psicologia del Deporte, 21(2), 223-231.

Balaguer, I., Castillo, I., \& Duda, J. (2008). Apoyo a la autonomía, satisfacción de las necessidades, motivación y bienestar en deportistas de competición: un análisis de la teoria de autodeterminación. [Autonomy, needs satisfaction, motivation and wellbeing support in competitive athletes: an analysis of the self-determination theory. In Spanish.] Revista de Psicologia del Deporte, 17(1), 123-139.

Biddle, S. (1999). Targeting goal: But which goal? Motivating the child in football. Insigh - The F. A. Coaches Association Journal, 4(2), 40.

Biddle, S., Wang, C.K.J., Kavussanu, M., \& Spray, C. (2003). Correlates of achievement goal orientations in physical activity: A systematic review of research. European Journal of Sport Science, 3(5), 1-20.

Buch, R., Nerstad, C.G., \& Safvenbom, R. (2017). The interactive roles of mastery climate and performance climate in predicting intrinsic motivation. Scandinavian Journal of Medicine and Science in Sports, 27(2), 245-253.

Castillo, I., Balaguer, I., \& Duda, J. (2000). Las orientaciones de meta y los motivos de prática deportiva en los jóvenes deportistas valencianos escolarizados. [Goal orientation and motives for sport participation in schooled young athletes from Valencia. In Spanish.] Revista de Psicologia del Deporte, 9(1-2), 37-50.

Chian, L., \& Wang, C. (2008). Motivational profiles of junior college athletes: A cluster analysis. Journal of Applied Social Psychology, 20, 37-50.

Chin, N.-S., Khoo, S., \& Low, W.-Y. (2012). Self-determination and goal orientation in track and field. Journal of Human Kinetics, 33, 151-161.

Cumming, J., Hall, C., Harwood, C., \& Gammage, K. (2002). Motivational orientations and imagery use: A goal profiling analysis. Journal of Sports Sciences, 20(2), 127-136.

Deci, E., \& Ryan, R. (1985). Intrinsic motivation and self-determination in human behavior. New York: Plenum.

Duda, J., \& Nicholls, J. (1992). Dimensions of achievment motivation in schoolwork and sport. Journal of Educational Psychology, 84(3), 290-299.

Etnier, J., Sidman, C., \& Hancock, L. (2004). An examination of goal orientation profiles and motivation in adult team sport. International Journal of Sport Psychology, 35, 173-188.

Fenton, S.A.M., Duda, J.L., \& Barrett, T. (2016). Optimising physical activity engagement during youth sport: A selfdetermination theory approach. Journal of Sports Sciences, 34(19), 1874-1884. doi:10.1080/02640414.2016.11 42104

Fonseca, A., \& Biddle, S. (1995). Versão portuguesa do Task and Ego Orientation in Sport Questionnaire (TEOSQ): Questionário sobre a orientação para a Tarefa e para o Ego no desporto (TEOSQp). [Portuguese version of the Task and Ego Orientation in Sport Questionnaire (TEOSQ): questionário sobre a orientação para a tarefa e para o ego no desporto (TEOSQp). In Portuguese.] Porto: FCDEF-UP.

Fonseca, A., \& Biddle, S. (1997). Questionário de Orientação para a Tarefa e para o Ego no Desporto. [Task and Ego Orientation in Sport Questionnaire.] Porto: FCDEF-UP.

Fonseca, A., \& Paula-Brito, A. (2000). Las concepciones sobre la competencia deportiva y los objetivos de logro. [Conceptions about sports competence and achievement objectives. In Spanish.] Revista de Psicologia del Deporte, 9(1-2), 159-176.

Fox, K., Goudas, M., Biddle, S., Duda, J., \& Armstrong, N. (1994). Children's task and ego goal profiles in sport. British Journal of Educational Psychology, 64(2), 253-261.

Georgiadis, M., Biddle, S., \& Auweele, Y. (2000). Cognitive, emotional and behavioural connotations of task and ego goal orientation profiles: An ideographic approach using hierarchical class analysis. International Journal of Sport Psychology, 32, 1-20.

Gillet, N., Vallerand, R., \& Paty, B. (2013). Situational motivational profiles and performance with elite performers. Journal of Applied Social Psychology, 43, 1200-1210.

Hodge, K., \& Petlichkoff, L. (2000). Goal profiles in sport motivation: A cluster analysis. Journal of Sport and Exercise Psychology, 22, 256-272. 
Horn, R. (2001). World-wide review of science and football research. Insight-The F. A. Coaches Association Journal, 4(4), 20-22.

Li, C.X., Wang, C.K.J., Pyun, D.Y., \& Kee, Y.H. (2013). Burnout and its relations with basic psychological needs and motivation among athletes: A systematic review and meta-analysis. Psychology of Sport and Exercise, 14(5), 692-700.

Lochbaum, M., Cetinkalp, Z.K., Graham, K.A., Wright, T., \& Zazo, R. (2016). Task and ego goal orientations in competitive sport: A quantitative review of the literature from 1989 to 2016. Kinesiology, 48(1), 3-29.

Lochbaum, M., Zazo, R., Cetinkalp, Z.K., Wright, T., Graham, K.A., \& Konttinen, N. (2016). A meta-analytic review of achievement goal orientation correlates in competitive sport: A follow-up to Lochbaum et al. (2016). Kinesiology, 48(2), 159-173.

Mallet, C., \& Hanrahan, S. (2004). Elite athletes: Why does the "fire" burn so brightly? Psychology of Sport and Exercise, 5, 183-200.

Nicholls, J. (1989). The competitive ethos and democratic education. Cambridge, MA: Harvard University Press.

Ntoumanis, N. (2001). Empirical links between achievement goal theory and self-determination theory in sport. Journal of Sports Sciences, 19(6), 397-409.

Olmedilla, A., Ortega, E., Andreu, M., \& Ortín, F. (2010). Programa de intervención psicológica en futbolistas: evaluación de habilidades psicológicas mediante el CPRD. [Psychological intervention program in footballers: evaluation of psychological abilities according to the CPRD. In Spanish.] Revista de Psicologia del Deporte, 19(2), 249-262.

Perreault, S., \& Vallerand, R. (1998). Créer un climat motivationnel: la motivation intrinsèque et extrinsèque dans le sport. [Creating a motivational climate: intrinsic and extrinsic motivation in sports. In French.] In E. Thill \& P. Fleurance (Eds.), Guide pratique de la préparation psychologique du sportif (pp. 93-108). Paris: Vigot.

Roberts, G. (2001). Understanding the dynamics of motivation in physical activity: The influence of achievement goals on motivational processes. In G. Roberts (Ed.), Advances in motivation in sport and exercise (pp. 79-100). Champaign, IL: Human Kinetics.

Ryan, R., \& Connell, J. (1989). Perceived locus of causality and internalization: Examining reasons for acting in two domains. Journal of Personality and Social Psychology, 57(5), 749-761.

Sarmento, H., Marcelino, R., Anguera, M., Campaniço, J., Matos, N., \& Leitão, J. (2014). Match analysis in football: A systematic review. Journal of Sports Sciences, 32(20), 1831-1843.

Shah, J., \& Gardner, W. (2008). Handbook of motivation science. New York: Guilford Press.

Smith, A.L., Balaguer, I., \& Duda, J.L. (2006). Goal orientation profile differences on perceived motivational climate, perceived peer relationships, and motivation-related responses of youth athletes. Journal of Sports Sciences, 24(12), 1315-1327.

Wagstaff, C.R. (2014). Emotion regulation and sport performance. Journal of Sport and Exercise Psychology, 36(4), 401-412.

Wang, C., \& Biddle, S. (2001). Young people's motivational profiles in physical activity: A cluster analysis. Journal of Sport and Exercise Psychology, 23, 1-22.

Wang, C., Liu, W., Sun, Y., Lim, B., \& Chatzisarantis, N. (2010). Chinese students' motivation in physical activity: Goal profile using Nicholl's achievement goal theory. International Journal of Sport and Exercise Psychology, 8, 284-301.

Wilson, F., Rodgers, W., Fraser, S., \& Murray, T. (2004). Relationships between exercise regulations and motivational consequences in university students. Research Quarterly for Exercise and Sport, 75(1), 81-91.

Zuber, C., Zibung, M., \& Conzelmann, A. (2015). Motivational patterns as an instrument for predicting success in promising young football players. Journal of Sports Sciences, 33(2), 160-168.

Submitted: April 17, 2017

Accepted: November 28, 2017

Published Online First: March 13, 2018

Correspondence to:

Hugo Sarmento, Ph.D.

Faculdade de Ciências do Desporto e Educação Física

Universidade de Coimbra, Estádio Universitário de

Coimbra

3040-156, Coimbra, Portugal

E-mail: hugo.sarmento@uc.pt 